\title{
Anthemis tinctoria L. var. tinctoria L. Bitkisine Ait Fenolik Bileşiklerin LC-ESI- MS/MS ile Miktar Tayini ve Bitkinin Biyolojik Aktivitelerinin Belirlenmesi
}

\author{
Quantification of Phenolic Compounds of Anthemis tinctoria L. var. tinctoria L. by LC- \\ MS/MS and Determination of Biological Activities of the Plant
}

\author{
Ahmet EMIR*1,a, Ceren EMIR ${ }^{1, b}$ \\ ${ }^{1}$ Ege Üniversitesi, Eczacllık Fakültesi, Farmakognozi Anabilim Dall, 35040, Bornova/İzmir, Türkiye
}

• Geliş tarihi / Received: 10.02.2020 • Düzeltilerek geliş tarihi / Received in revised form: 30.08.2020 • Kabul tarihi / Accepted: 04.09.2020

\begin{abstract}
$\ddot{O} z$
Mevcut çalışmada, Tire/İzmir'den toplanan ve halk arasında, boyacı papatyası veya sarı papatya olarak adlandırılan Anthemis tinctoria var. tinctoria bitkisi fenolik profili ve biyolojik aktiviteleri bakımından incelenmiştir. Toplam fenolik ve flavonoit içeriği spektrofotometrik olarak belirlenmiş olup, 30 adet fenolik bileşiğin dedeksiyonu ve miktar tayini LC-ESI-MS/MS cihazı ile yapılmıştır. Bitkinin metanol ekstresine ait asetilkolinesteraz, bütirilkolinesteraz ve tirozinaz enzim inhibisyonları 96 kuyucuklu mikroplaka okuyucu ile saptanmıştır. Ayrıca bitkinin antioksidan kapasite tayini DPPH ve CUPRAC yöntemleriyle belirlenmiştir. Metanol ekstresinin toplam fenolik ve flavonoit miktarları sirasıyla 21.4 \pm 4.2 (mg GAE/g ekstre) ve $9.7 \pm 2.56$ (mg QE/g ekstre) olarak bulunmuştur. Miktar tayininde, fenolik asit olarak 3-hidroksibenzoik asit (1167.3 $\pm 0.72 \mu \mathrm{g} / \mathrm{g}$ ekstre) ve ferulik asit $(845.8 \pm 1.98 \mu \mathrm{g} / \mathrm{g}$ ekstre), flavonoit olarak morin $(1598.4 \pm 2.15 \mu \mathrm{g} / \mathrm{g}$ ekstre) ve kersetin $(1416.0 \pm 1.83 \mu \mathrm{g} / \mathrm{g}$ ekstre) bileşikleri en yüksek konsantrasyonda bulunmuştur. Asetilkolinesteraz, bütirilkolinesteraz ve tirozinaz enzim inhibisyonlarının $\mathrm{IC}_{50}$ değerleri ise sırasıyla $254.7 \pm 4.86$ $\mu \mathrm{g} / \mathrm{mL}, 166.2 \pm 3.74 \mu \mathrm{g} / \mathrm{mL}$ ve $415.7 \pm 1.85 \mu \mathrm{g} / \mathrm{mL}$ olarak hesaplandi. Ayrıca bitkinin antioksidan kapasitesi sirasıyla $302.18 \pm 2.74$ ve $514.62 \pm 3.82 \mathrm{mg} \mathrm{TE} / \mathrm{g}$ ekstre olarak bulunmuştur.
\end{abstract}

Anahtar kelimeler: Anthemis tinctoria, Fenolikler, Kolinesterazlar, Tirozinaz

\begin{abstract}
In the present study, Anthemis tinctoria var tinctoria plant, collected from Tire / Izmir and named as the painter's daisy or yellow daisy among the people, was examined in terms of its phenolic profile and biological activities. Total phenolic and flavonoids content were determined spectrophotometrically. Detection and quantification of 30 phenolic compounds were performed by LC-ESI-MS/MS. Acetylcholinesterase, butyrylcholinesterase and tyrosinase enzyme inhibition of methanol extract of the plant were determined by 96-well microplate reader. In addition, antioxidant capacity of the plant was determined by DPPH and CUPRAC methods. Total phenolic and flavonoid contents of

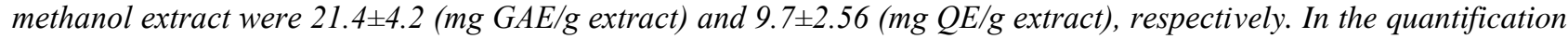
assay, 3-hydroxybenzoic acid (1167.3 $\pm 0.72 \mu \mathrm{g} / \mathrm{g}$ extract) and ferulic acid ( $845.8 \pm 1.98 \mu \mathrm{g} / \mathrm{g}$ extract) as phenolic acid, morin $(1598.4 \pm 2.15 \mu \mathrm{g} / \mathrm{g}$ extract) and quercetin $(1416.0 \pm 1.83 \mu \mathrm{g} / \mathrm{g}$ extract) as flavonoids were found at the highest concentration. $I_{50}$ values of acetylcholinesterase, butyrylcholinesterase and tyrosinase inhibition were $254.7 \pm 4.86$ $\mu \mathrm{g} / \mathrm{mL}, 166.2 \pm 3.74 \mu \mathrm{g} / \mathrm{mL}$ and $415.7 \pm 1.85 \mu \mathrm{g} / \mathrm{mL}$, respectively. In addition, the antioxidant capacity of the plant was found as $302.18 \pm 2.74$ and $514.62 \pm 3.82 \mathrm{mg}$ TE/g extract, respectively.
\end{abstract}

Keywords: Anthemis tinctoria, Phenolics, Cholinesterases, Tyrosinase

\footnotetext{
*a Ahmet EMIR; ahmet.emir@ege.edu.tr, Tel: (0505) 39321 09, orcid.org/0000-0002-0971-7716

${ }^{\mathrm{b}}$ orcid.org/0000-0001-8516-9830
} 


\section{Giriş}

Sekonder metabolitler, kimyasal yapıları birbirinden oldukça farklı olan ve bitkilerdeki farklı yollardan sentezlenen maddelerdir. $\mathrm{Bu}$ metabolitler bitkilerin temel işlevleri için doğrudan gerekli değildir, ancak fizyolojik faaliyetler için olduğu kadar insektisitlerden, oksidan ajanlardan ve ultraviyole radyasyon gibi dış etkenlerden korunmak amaciyla sentezlendiği düşünülmektedir. Bitki fenolikleri de biyogenetik olarak şikimik asit ya da malonat/asetat yolakları aracılığıyla oluşturulan, temel kimyasal iskeletlerine göre 16 gruba ayrılan en büyük sekonder metabolit gruplarından biridir (Lattanzio, 2013). Günümüzde birçok araştırmac1, çok çeşitli biyolojik ve farmakolojik etkileri nedeniyle fenolik bileşiklere odaklanmıştır. Kimyasal yapılarındaki fenil halkaları ve hidroksil grupları, bu moleküllerin güçlü antioksidan aktivite göstermesine neden olur. Redoks özellikleri, reaktif oksijen türlerini etkisizleştirmeyi, oksidanları indirgemeyi ve metal şelatlamayı sağlar (Afanasev vd., 1989). Ayrıca, fenolik bileşiklerin $\alpha$-amilaz ve $\alpha$ glukosidaz, lipaz, kolinesterazlar ve tirozinaz gibi enzimlere karşı önleyici potansiyelleri ile ilgili çalışmalar gün geçtikçe artmaktadır (Gonçalves ve Romano, 2017). Enzimler, çeşitli biyolojik yaşam süreçleri ve hastalıkların patofizyolojisindeki katalitik rolleri nedeniyle birçok kronik hastalıkta temel moleküler hedeftirler. Bunu, pazarlanan tüm küçük moleküllü ilaçların \% $\quad 47$ 'sinin enzimlerin inhibisyonunu etkilemesi açıkça desteklemektedir (Hopkins ve Groom, 2002). Yaygin olarak kullanılan bu ilaçlara örnek olarak kolinesteraz inhibitörleri verilebilir. Kolinesteraz inhibitörleri, belirgin ve kesin bir tedavisi olmayan nörodejeneratif Alzheimer hastalığının semptomatik tedavisinde en fazla kullanılan ilaçlardır. Bu ilaç etken maddelerinden takrin, rivasitigmin ve memantin hem asetilkolinesteraz (AChE) hem de butirilkolinesteraz (BuChE) enzimleri üzerinde etkiliyken, galantamin ve donezepil AChE için seçicidir. $\mathrm{Bu}$ ilaçlar, kolinerjik etkinliği arttırarak hastanın yaşam kalitesinde artış ve hastalık evresinde stabilizasyon sağlamaktadır. Bununla birlikte, bu ilaçların mide bulantısı, kusma, ishal, baş dönmesi, karın ağrısı ve baş ağrısı gibi hastaların yaşam kalitesini olumsuz etkileyen birçok yan etkisi vardır (Weinstock, 1999). Bu nedenle, minimal yan etkileri olan doğal enzim inhibitörlerini bulma çalışmaları birçok araştırmacının çalışma konusu olmuştur. Diğer yandan, glikoprotein yapısına sahip olan tirozinaz enzimi ise, insanda temel olarak tirozinin monofenolaz etkisi ile hidroksilasyonu ve 3,4dihidroksifenilalaninin (L-DOPA) difenolaz etkisi ile o-dopakinona oksidasyonu ile melanin sentezinde rol oynamaktadır. Melaninin fotoprotektif etkisine rağmen, fazla miktarda sentezlenmesi farklı deri hastalıklarına sebep olabilmektedir. Ayrıca meyve ve sebzelerde polifenolik bileşiklerin oksidasyonuna bağlı olarak gerçekleşen renk kararmasından yine tirozinaz enzimi sorumludur. $\mathrm{Bu}$ etkilerinin yanında, beyinde tirozinaz enziminin katalizlediği bir reaksiyon sonucu oluşan nöromelanin, Parkinson hastalığındaki duyarlı nöronlarda nörodejenerasyona neden olmaktadır (Martinez ve Whitaker, 1995; Asanuma vd., 2003; Zolghadri vd., 2019). $\mathrm{Bu}$ sebeplerden dolay1 tirozinaz enzimini inhibe eden doğal ürünlerin araştırılması da önemli hale gelmiştir.

Anthemis cinsi, dünya genelinde yaklaşık 210 türle temsil edilen ve Compositae familyasının en geniş ikinci genusudur. Ülkemizde ise 83 taksonu bulunmakla birlikte bunların \% 54'ü endemiktir (Bremer ve Humpries, 1993; Güner vd., 2000). Halk arasında, boyacı papatyası veya sarı papatya olarak adlandırılan Anthemis tinctoria var. tinctoria bitkisi grimsi-yeşil renkte, $20-50 \mathrm{~cm}$ yükseklikte, sarı çiçekli ve çok yıllık bir bitki olup, Anadolu'da yaygın bir şekilde bulunmaktadır (Baytop, 1999). Etnobotanik çalışmalarda A. nobilis bitkisinin diyaforetik, karminatif (Al-Snafi, 2016), A. cretica'nın karın ağrısı ve böbrek taşında (Uğurlu ve Seçmen, 2008), A. cotula' nın psöriazis, ateş, gastrointestinal sistem sorunlarında (Shawahna ve Jaradat, 2017) yine A. creatica ssp. tenuiloba ve A. austriaca bitkilerinin infüzyonlarının karın ağrısına dekoksiyonlarının hemoroid ve soğuk algınlığına karşı kullanıldığı belirtilmiştir (Honda vd., 1996). A. tinctoria var. tinctoria çiçeklerinden hazırlanan dekoksiyonun antidiyabetik ve antispazmodik amaçlı kullanıldığının rapor edildiği çalışmada endemik $A$. wiedemanniana bitkisinin sedatif, antispazmodik etkili ve üriner problemlerde kullanıldığı bildirilmiştir (Cakilcioglu vd., 2011). Daha önce yayınlanan bilimsel araştırmalarda, Anthemis türlerine ait yapılan fitokimyasal çalışmalar sonucu elde edilen polifenolik bileşikler ile mono- ve seskiterpenlerin antioksidan (Papaioannoua vd., 2007), antiproliferatif (Conforti vd., 2012), antidiabetik (Afifi ve Kasabri, 2013), antiprotozoal (De Mieri vd., 2017), antispazmodik (Karim vd., 2010) potansiyellerine sahip olduğu rapor edilmiştir. Yine literatürde, farklı Anthemis türlerinin farklı çözücülerle hazırlanmış ekstrelerinin LC-MS ve 
HPLC uygulamaları aracılığıyla fenolik bileşimlerinin incelendiği çalışmalar mevcuttur. $A$. kotschyana türünün etanol ve su ekstrelerinde LCMS/MS dedeksiyonunda, 27 bileşik arasında ramnetin ve kinik asit majör maddeler olarak belirlenmiştir (Bursal vd., 2020). Bir diğer örnek ise nadir bir endemik olan A. fulvida (= Cota fulvida)'nın metanol ekstresine aittir. $\mathrm{Bu}$ çalışmada şiringik asit, kaftarik asit, kinik asit türevleri, kersetin glikozitleri ve luteolinin varlığının tespit edildiği belirlenmiştir (Özek vd., 2019). Bunlara ek olarak, polifenolik içeriğiyle birlikte seskiterpenik maddelerinde varlığının tespit edildiği makalelerde A. tinctoria var. pallida, A. cretica subsp. tenuiloba ve A. cotula bitkileri çalışılmıştır (Orlando vd., 2019; Sut vd., 2019). Görüldüğü gibi literatürde, A. tinctoria L. bitkisinin farklı varyeteleri ile ilgili çalışmalar yer alırken, A. tinctoria var. tinctoria taksonu hakkında sınırlı sayıda araştırma rapor edilmiştir. Bunlardan, Papaioannoua vd., (2007)'nin yapmış oldukları çalışmada, Yunanistan'dan toplanan A. tinctoria subsp. tinctoria var. pallida bitkisinin fitokimyasal izolasyonu sonucu konduritol glikozidi, nikotiflorin, izokersetin, rutin ve patulitrin maddeleri elde edilmiş ve antioksidan aktiviteleri incelenmiştir. Yine Beypazarı/Ankara bölgesinden toplanan bu Anthemis türünün antiviral aktivitesi ve sitotoksisitesi araştırılmıştır (Orhan vd., 2009). Bir diğer multidisipliner çalışmada ise, A. tinctoria var. tinctoria bitkisinin etanol ve su ekstreleriyle harmanlanmış viskoz, pamuk, yün gibi kumaşların boyama, dayanıklılık, sitotoksisite özelliklerine bakılmıştır (Eser vd., 2017).

Tüm bu bilgiler 1şığında, söz konusu Anthemis tinctoria var. tinctoria bitkisinin geniş kapsamda biyoaktif fenolik bileşiklerinin miktar tayini LCESI-MS/MS cihazıyla gerçekleştirilmiş olup spektrofotometrik yöntemlerle, bitkinin toplam fenolik içeriği, toplam flavonoit içeriği, antioksidan kapasitesi, asetilkolinesteraz, bütirilkolinesteraz ve tirozinaz enzim inhibitör aktiviteleri tarafımızdan saptanmıştır.

\section{Materyal ve Metot}

\subsection{Kimyasallar}

LC-MS/MS çalışmalarında standart olarak kullanılan (+)-kateşin, (-)-epikateşin, (-)epigallokateşin gallat, benzoik asit, 3hidroksibenzoik asit, 4-hidroksibenzoik asit, kateşol, krisin, ferulik asit, 3-hidroksiflavon, galangin, genistein, izoramnetin, kemferol, luteolin, $p$-kumarik asit, morin, mirsetin, naringenin, fenil asetat, daidzein, viteksin, kersetin, 3-O-metilkersetin, sirinjik asit, vanillik asit, gallik asit, fisetin, hesperidin, rutin; ve enzim inhibisyon aktivitelerinde kullanılan AChE (Electrophorus electricus), BuChE (at serumu), Asetiltiyokolin/Butiriltiyokolin iodid, DTNB (Ellman reaktifi) [5,5'-ditiyo-bis-(2-nitrobenzoik asit)], galantamine hidrobromür, tirozinaz (mantar), L-Dopa ve $\alpha$-kojik asit Sigma-Aldrich (St. Louis, MO, USA) markasından temin edilmiştir. Folin-Ciocalteu reaktifi, sodyum karbonat, alüminyum klorür, potasyum asetat ve dimetilsülfoksit (DMSO) ile antioksidan aktivite çalışmalarında kullanılan 1,1-difenil-2pikrilhidrazil, neokuprin ve bakır (II) klorür yine aynı firmadan alınmıştır. Ayrıca ekstraksiyonda ve MS analizinde kullanılan ultra saf su, metanol ve formik asit analitik (LC grade, Sigma-Aldrich) kalitede tercih edilmiştir.

\subsection{Bitki Örneği}

Anthemis tinctoria var. tinctoria bitkisi, Tire/İzmir' den Haziran 2018 tarihinde toplanmıştır. Toplanan bitki oda sıcaklığında ve karanlık ortamda saklanmıştır. Tür teşhisi Dr. Ahmet Emir tarafından yapılmış olup, bitkiye ait herbaryum örneği Ege Üniversitesi Eczacil1k Fakültesi Farmakognozi Anabilim Dalı'nda 1630 kod numarası ile bulunmaktadır.

\subsection{Bitki Ekstresinin Hazırlanışı}

Ekstraksiyon işlemi önceki çalışmamızda (Emir vd., 2020a) tarif edildiği şekilde geçekleştirildi. Oda sıcaklığında kurutulmuş ve toz edilmiş bitkinin toprak üstü kısmından bir gram tartılarak falkon tüpe aktarıld. Daha sonra tüp içerisine 20 $\mathrm{mL}$ metanol (LC grade) konulup, ekstraksiyon için rotator cihazında (ISOLAB Laborgeräte $\mathrm{GmbH}$ ) bir saat süre ile çalkalandı ve metanollü kısım süzülerek $100 \mathrm{~mL}$ 'lik balona aktarıldı. Ektraksiyon işlemi $3 \mathrm{kez}$ tekrarlandı ve süzüntü metanolden rotavapor (Büchi, Labortechnik AG, Flawil, Switzerland) cihazında $40^{\circ} \mathrm{C}^{\prime} \mathrm{de}$, düşük basınç altında kurtarıldı ve metanol ekstresi elde edildi. Bitkinin metanol ekstresi kromatografik analiz ve diğer biyolojik aktivitelerde kullanılmak üzere $4^{\circ} \mathrm{C}$ 'de ve karanlık ortamda bekletildi. LCMS/MS çalışması için $0.22 \mu \mathrm{m}$ PTFE filtre kullanıldi.

\subsection{Toplam Fenolik İçeriği}

Ekstrenin toplam fenolik içerik tayini, bazı modifikasyonlar ile birlikte belirtilen metoda (Singleton vd., 1999) göre yapıldı. Flakonlara 1 
$\mathrm{mg} / \mathrm{mL}$ konsantrasyonda $1 \mathrm{~mL}$ ekstrakt, FolinCiocalteu reaktifi (1/10 oranında seyreltilmiş) ve 4 $\mathrm{mL}$ sodyum karbonat çözeltisi (\%7.5) ilave edildi. $25^{\circ} \mathrm{C}^{\prime} \mathrm{de} 20$ dakika inkübasyondan sonra, absorbans değerleri $765 \mathrm{~nm}$ ' de (Thermo Scientific Evolution Array) ölçüldü. Kalibrasyon eğrisi için benzer prosedür uygulanmış olup, pozitif kontrol için gallik asit kullanıldı ve sonuçlar gallik asit eşdeğerleri (mg GAE/g ekstre) olarak ifade edildi.

\subsection{Toplam Flavonoit İçeriği}

Ekstrenin toplam flavonoit içeriği, $\mathrm{AlCl}_{3}$ metoduna göre (Dziri vd., 2012) saptand. Buna göre, $2 \mathrm{~mL}$ ekstrakt, $0.1 \mathrm{~mL} \% 10^{\prime}$ luk bir $\mathrm{AlCl}_{3}$ çözeltisi, $0.1 \mathrm{~mL}$ potasyum asetat ve $2.8 \mathrm{~mL}$ distile su bir flakona ilave edildi. 30 dakika süre ile oda sıcaklığında inkübasyondan sonra, absorbans $415 \mathrm{~nm}$ ' de (Thermo Scientific Evolution Array) ölçüldü. Kersetin pozitif kontrol olarak kullanıldı ve sonuçlar kersetin eşdeğerleri (mg KE/g ekstre) olarak ifade edildi.

\subsection{Fenolik Bileşiklerin Saptanması ve Miktar Tayini}

30 tane fenolik bileşiğin analizi, TSQ Quantum ${ }^{\mathrm{TM}}$ Access MAX Triple Quadrupole Mass Spectrometer (Thermo Scientific ${ }^{\mathrm{TM}}$ ) cihaz1 kullanılarak gerçekleştirildi. Kromatografik ayrım için GL Sciences ODS $\mathrm{C}_{18}(150 \mathrm{~mm} \times 4.6 \mathrm{~mm} \times 5$ $\mu \mathrm{m})$ kolon ve gradiyent mobil faz sistemi kullanıldı (Emir vd., 2020b). Solvan A olarak 0.1 $\%$ formik asit içeren su, solvan B olarak $0.1 \%$ formik asit içeren metanol kullanıldı (Tablo 1). Mobil fazın akış hızı $1.0 \mathrm{~mL} / \mathrm{dk}$, enjeksiyon hacmi ise $5 \mu \mathrm{L}$ olacak şekilde ayarlandı. Kolon sıcaklığ $25^{\circ} \mathrm{C}$ 'de sabitlendi. Cihaza ait ESI parametreleri: iyon kaynağı (HESI) 3000 püskürtme voltaj1, kapiler sicaklık $400^{\circ} \mathrm{C}$, buharlaştırıcı sıcaklığ $500^{\circ} \mathrm{C}$, sheath gazı, aux gazı ve sweep gazı akış hızı sırasıly 75 arb, 20 arb ve 0 arb şeklindedir; bileşiklere ait MS parametreleri ise Tablo 2'de ayrıntılı şekilde yer almaktadır. Miktar tayini için, external standart yöntem kullanıldı. Her bir fenolik bileşiğin miktarı kalibrasyon eğrileri kullanılarak $\mu \mathrm{g} / \mathrm{g}$ ekstre şeklinde ifade edildi (Tablo 3).

\subsection{Anti-kolinesteraz Aktivite}

Ekstrelerin asetilkolinesteraz ve bütirilkolinesteraz inhibitör aktivitesi Ellman (1961) metodunda yapılan birtakım modifikasyonlarla, 96 kuyucuklu mikroplaka okuyucu (Varioskan Flash Multimode Reader, Thermo Scientific, USA) kullanılarak yapildı. Ekstreye, $0.05 \mathrm{M}$ fosfat tamponu kullanilarak $0.001-1000 \mathrm{mg} / \mathrm{mL}$ konsantrasyon aralığında olacak şekilde seyreltmeler yapıldı. Plakaya aktarılan örnekler üzerine $0.25 \mathrm{U} / \mathrm{mL}$ enzim ilave edildi ve substrat konulmadan önce $30 \mathrm{dk}$ inkübasyona bırakıldı. Daha sonra substrat olarak $0.24 \mathrm{mM}$ asetiltiyokolin iodid/bütiriltiyokolin iodid çözeltisi ve $0.2 \mathrm{mM}$ Ellman reaktifi (5,5dithiobis-2-nitrobenzoic acid) (DTNB) ilave edildi. Son olarak mikroplaka okuyucu yardımıyla $405 \mathrm{~nm}$ 'de absorbans değişimine dayalı ölçümler yapıldı. Standart olarak galantaminin kullanıldığ deneyde enzim inhibisyonlarına ait $\mathrm{IC}_{50}$ değerleri üç bağımsız ölçümden alınan sonuçlara göre GraphPad Prism V5.0 (GraphPad Software, San Diego, CA, USA) yazılımı kullanılarak hesaplandi.

Tablo 1. Gradiyent faz değerleri

\begin{tabular}{llll}
\hline Zaman & A \% & B\% & Akış $\boldsymbol{\mu l} / \mathbf{d k}$ \\
\hline 0 & 95 & 5 & 1000 \\
1.50 & 80 & 20 & 1000 \\
3.00 & 70 & 30 & 1000 \\
4.75 & 50 & 50 & 1000 \\
6.25 & 30 & 70 & 1000 \\
7.50 & 20 & 80 & 1000 \\
10.0 & 10 & 90 & 1000 \\
12.5 & 5 & 95 & 1000 \\
15.0 & 95 & 5 & 1000 \\
\hline
\end{tabular}

\subsection{Anti-tirozinaz aktivite}

Ekstrelerin tirozinaz inhibisyon aktivitesi modifiye edilmiş dopakrom yöntemi kullanılarak belirlendi (Masuda vd., 2005). Deneyler, 96 kuyucuklu mikroplaka okuyucu kullanılarak gerçekleştirildi. \% 5 DMSO içeren $1 / 15 \mathrm{M}$ potasyum fosfat tamponu ( $\mathrm{pH}$ 6.8), 7 farkl1 konsantrasyondaki metanol ekstresi (1000, 750, $500,250,100,10,1 \mu \mathrm{g} / \mathrm{mL}$ ) ve tirozinaz enzim çözeltisi (46 U/mL) hazırlamak için kullanıldı. Ekstre ve enzim kuyucuklara eklendikten sonra 25 ${ }^{\circ} \mathrm{C}$ ' de 10 dakika inkübe edilip, $2.5 \mathrm{mM}$ L-Dopa substrat çözeltisi ilave edildi. Daha sonra tekrar 25 ${ }^{\circ} \mathrm{C}$ ' de 20 dakika inkübe edildi ve absorbans 475 nm' de ölçüldü. Üç bağımsız ölçümden alınan sonuçlara göre GraphPad Prism V5.0 yazılımı kullanılarak $\mathrm{IC}_{50}$ değerleri hesaplandı. Pozitif standart olarak $\alpha$-kojik asit kullanıldı. 
Tablo 2. Bileşiklere ait MS/MS parametreleri

\begin{tabular}{|c|c|c|c|c|c|}
\hline $\begin{array}{l}\text { Molekül } \\
\text { No } \\
\end{array}$ & Molekül Adı & $\begin{array}{l}\text { Kollezyon } \\
\text { Enerjisi }\end{array}$ & $\begin{array}{l}\text { İyonizasyon } \\
\text { Modu } \\
\end{array}$ & Prekürsör İyon & Prodak İyon \\
\hline 1 & Kateşol & 27 & Negatif & 109.22 & 108.10 \\
\hline 2 & (+)-Kateşin & 22 & Negatif & 289.10 & 203.07 \\
\hline 3 & (-)-Epikateşin & 15 & Negatif & 291.22 & 139.10 \\
\hline 4 & (-)-Epigallokateşin gallat & 15 & Negatif & 549.18 & 139.10 \\
\hline 5 & Benzoik asit & 15 & Negatif & 121.18 & 77.23 \\
\hline 6 & 3-Hidroksibenzoik asit & 15 & Negatif & 137.18 & 93.18 \\
\hline 7 & 4-Hidroksibenzoik asit & 15 & Negatif & 137.15 & 93.15 \\
\hline 8 & $p$-Kumarik asit & 13 & Negatif & 163.01 & 119.08 \\
\hline 9 & Vanillik asit & 7 & Negatif & 167.10 & 152.60 \\
\hline 10 & Gallik asit & 15 & Negatif & 169.07 & 125.02 \\
\hline 11 & Ferulik asit & 15 & Negatif & 193.04 & 134.10 \\
\hline 12 & Sirinjik asit & 15 & Negatif & 191.11 & 182.18 \\
\hline 13 & Daidzein & 34 & Negatif & 252.84 & 223.10 \\
\hline 14 & Krisin & 35 & Negatif & 253.18 & 143.06 \\
\hline 15 & Kemferol & 35 & Negatif & 285.10 & 238.95 \\
\hline 16 & Luteolin & 30 & Negatif & 284.96 & 238.95 \\
\hline 17 & Fisetin & 30 & Negatif & 285.10 & 135.01 \\
\hline 18 & Morin & 23 & Negatif & 301.22 & 150.94 \\
\hline 19 & Kersetin & 26 & Negatif & 301.20 & 150.94 \\
\hline 20 & 3-O-Metilkersetin & 20 & Negatif & 315.10 & 290.99 \\
\hline 21 & İzoramnetin & 35 & Negatif & 315.09 & 300.02 \\
\hline 22 & Galangin & 25 & Negatif & 271.20 & 153.11 \\
\hline 23 & Mirsetin & 20 & Negatif & 317.05 & 191.00 \\
\hline 24 & Viteksin & 20 & Negatif & 431.29 & 310.96 \\
\hline 25 & Hesperidin & 20 & Negatif & 609.40 & 300.88 \\
\hline 26 & 3-Hidroksiflavon & 24 & Negatif & 239.10 & 165.08 \\
\hline 27 & Naringenin & 22 & Negatif & 271.05 & 151.01 \\
\hline 28 & Genistein & 30 & Negatif & 271.09 & 153.11 \\
\hline 29 & Rutin & 35 & Negatif & 609.24 & 299.91 \\
\hline 30 & Fenil asetat & 10 & Negatif & 137.12 & 95.15 \\
\hline
\end{tabular}

\subsection{Ekstrenin Antioksidan Aktivitelerinin Saptanmast}

\subsubsection{DPPH Yöntemi}

1000-1 ppm aralığındaki farklı konsantrasyonlarda hazırlanan metanol ekstrelerinde, kararlı yapıda bir azot radikali olan 1,1-difenil-2-pikrilhidrazil (DPPH) kullanılarak Blois'in (1958) metoduna göre çalışıldı. Belirlenen konsantrasyondaki ekstreden $3 \mathrm{~mL}$ cam flakona konuldu. Üzerine, $1 \mathrm{mg}$ tartılarak balon jojede hazırlanan $0.1 \mathrm{mM}$ DPPH çözeltisinden $1 \mathrm{~mL}$ ilave edildi. Daha sonra karanlık ortamda $30 \mathrm{dk}$ bekletildikten sonra absorbans değerleri spektrofotometrede (Thermo Scientific, Evolution Array) 517 nm' de ölçüldü. Kontrol grubunda ise $1 \mathrm{~mL}$ DPPH çözeltisi ile 3 $\mathrm{mL}$ metanolden oluşan karışım $30 \mathrm{dk}$ karanlık ortamda bekletildikten sonra aynı şartlarda absorbans ölçümü gerçekleştirildi. Üç paralel ile gerçekleştirilen çalışmada pozitif standart olarak troloks kullanıldı ve sonuçlar troloks ekivalanı olarak (mg TE/g ekstre) verildi.

\subsubsection{CUPRAC Yöntemi}

Bakır indirgeme antioksidan kapasite yöntemi olan (CUPRAC) metodunda, $\mathrm{Cu}$ (II)' nin indirgenmesi sonucu oluşan $\mathrm{Cu}$ (I)' in neokuprin ile kompleks oluşturma esasına göre çalışıldı (Apak vd., 2008). CUPRAC reaktifi düşük redoks potansiyeline sahip olduğu için, şeker ve sitrik asit gibi gerçekte antioksidan olmayan fakat indirgeyici özelliği bulunan maddelerin girişim yapmasını engeller. Ayrıca, bu yöntemde tiyol bazlı antioksidanlar hızlı bir şekilde reaksiyon verir. Ölçümler yapılmadan önce deneyde kullanılacak çözeltiler hazırlandı. Öncelikle $\mathrm{CuCl}_{2}$ ' den $0.134 \mathrm{~g}$ tartılarak balonjojede $10 \mathrm{mM}$ ' lık çözeltisi hazırlandı. Daha sonra neokuprin $0.023 \mathrm{~g}$ tart1larak balon jojede $7.5 \mathrm{mM}^{\prime}$ l1k çözeltisi elde edildi. Deney ortamının $\mathrm{pH}^{\prime}$ inı ayarlamak için 19,27 g amonyum asetat tartılarak $1 \mathrm{M}$ amonyum asetat tamponu hazırlandı. Farklı konsantrasyonlarda hazırlanan metanol ekstreleri, $\mathrm{pH}=7.0$ 'de neokuprin ile bakır (II)'nin karışımı ile muamele edildikten sonra $30 \mathrm{dk}$ karanlık ortamda inkübasyona birakıldı. Daha sonra absorbans değerleri $450 \mathrm{~nm}$ ' de ölçüldü. Üç paralel ile gerçekleştirilen çalışmada pozitif standart olarak 
troloks kullanıldı ve sonuçlar troloks ekivalanı olarak (mg TE/g ekstre) verildi.

\section{Bulgular}

Kolay uygulanabilen, basit ve etkili bir ekstraksiyon metodu uygulanarak, ekstrede \% 27 verim elde edildi. Ekstrenin toplam fenolik ve flavonoit içeriği sırasıyla 21.4 \pm 4.2 (mg GAE/g ekstre) ve 9.7 \pm 2.56 (mg QE/g ekstre) olarak bulundu. Hazırlanan ekstre üzerinde 30 adet fenolik bileşiğin varlığ MS/MS cihazı kullanılarak yapıldı ve sonuçlar $\mu \mathrm{g} / \mathrm{g}$ ekstre olarak verildi. Ekstre ve standart madde karışımına ait kromatogramlar sırasıyla Şekil 1 ve 2' de verilmiştir. Bunlardan 24 tanesinin miktar tayini gerçekleştirildi; (-)epikateşin, (-)-epigallokateşin gallat, daidzein ve fisetin eser miktarda bulunurken, (+)-kateşin ve krisin bileşiklerinin varlıkları örnekte saptanmadı (Tablo 3). Yapilan biyolojik aktivite deneylerine ait sonuçlar Tablo 4' de verilmiştir. DPPH ve CUPRAC yöntemleriyle yapılan antioksidan kapasite tayini deneylerinde ise sonuçlar sırasıyla $302.18 \pm 2.74$ ve $514.62 \pm 3.82 \mathrm{mg} \mathrm{TE} / \mathrm{g}$ ekstre olarak bulundu. Metanol ekstresinin, asetilkolinesteraz ve bütirilkolinesteraz enzim inhibisyonlarının çalışıldığı deneyde galantamin hidrobromür standart olarak kullanıld1 ve $\mathrm{IC}_{50}$ değerleri sirasiyla $0.106 \pm 0.05 \mu \mathrm{g} / \mathrm{mL} \quad$ ve $1.04 \pm 0.12 \mu \mathrm{g} / \mathrm{mL}$ olarak hesapland1. Örneğimizde ise bu değerler $254.7 \pm 4.86 \mu \mathrm{g} / \mathrm{mL}$ ve $166.2 \pm 3.74$ $\mu \mathrm{g} / \mathrm{mL}$ olarak saptandi. Anti-tirozinaz aktivite deneyinde $\alpha$-kojik asit pozitif standart olarak kullanıldı. Standart bileşiğe ve ekstreye ait $\mathrm{IC}_{50}$ değerleri sirasıyla $7.9 \pm 0.54 \mu \mathrm{g} / \mathrm{mLve} 415.7 \pm 1.85$ $\mu \mathrm{g} / \mathrm{mL}$ olarak hesapland.

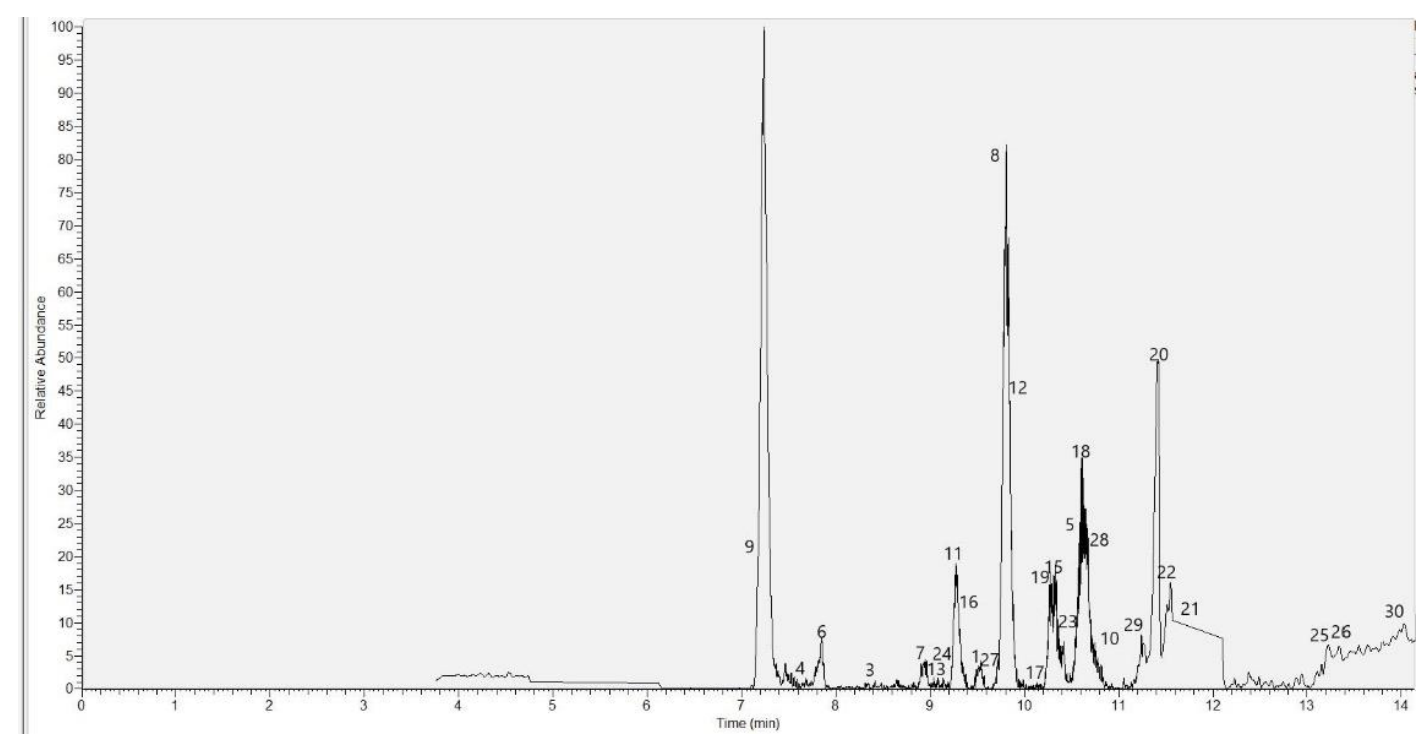

Şekil 1. Ekstreye ait MS/MS kromatogramı

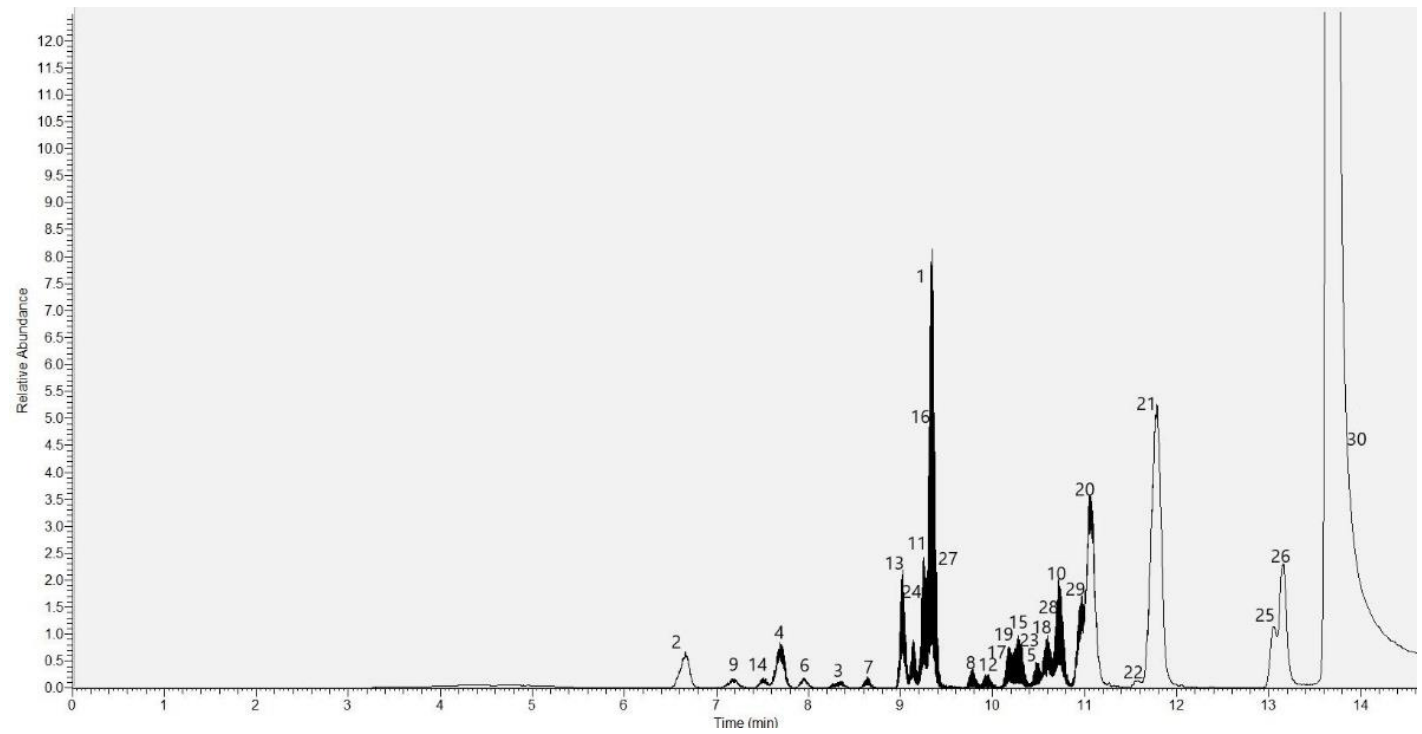

Şekil 2.Standart madde karışımına ait MS/MS kromatogramı 
Tablo 3. LC-MS/MS analiz sonuçları

\begin{tabular}{|c|c|c|c|c|c|c|c|}
\hline $\begin{array}{l}\text { Molekül } \\
\text { No } \\
\end{array}$ & Molekül Adı & $\begin{array}{l}\text { Miktar } \\
(\mu \mathrm{g} / \mathrm{g} \text { ekstre) }\end{array}$ & Doğrusal denklem & $\mathbf{R}^{2}$ & $\begin{array}{l}\text { LOD } \\
\text { (ng/ml) }\end{array}$ & $\begin{array}{l}\text { LOQ } \\
\text { (ng/ml) }\end{array}$ & $\begin{array}{l}\text { RSS, \% } \\
(10 \mu \mathrm{g} / \mathrm{ml})\end{array}$ \\
\hline 1 & Kateşol & $53.3 \pm 1.06$ & $y=2.7042 x+4.0149$ & 0.9982 & 14 & 45 & 1.26 \\
\hline 2 & (+)-Kateşin & $*$ & - & - & 32 & 95 & 0.95 \\
\hline 3 & (-)-Epikateşin & $\mathrm{T}$ & - & - & 18 & 55 & 0.58 \\
\hline 4 & (-)-Epigallokateşin gallat & $\mathrm{T}$ & - & - & 21 & 62 & 0.73 \\
\hline 5 & Benzoik asit & $82.9 \pm 0.55$ & $y=50.437 x+99.762$ & 0.9972 & 9 & 28 & 1.16 \\
\hline 6 & 3-Hidroksibenzoik asit & $1167.3 \pm 0.72$ & $y=8.7122 x-170.8$ & 0.9985 & 15 & 44 & 1.43 \\
\hline 7 & 4-Hidroksibenzoik asit & $246.7 \pm 1.68$ & $y=14.089 x+106.25$ & 0.9993 & 8 & 25 & 0.81 \\
\hline 8 & $p$-Kumarik asit & $178.7 \pm 0.23$ & $y=42.156 x+245.83$ & 0.9995 & 17 & 53 & 0.26 \\
\hline 9 & Vanillik asit & $51.0 \pm 1.03$ & $y=2.9519 x+0.2917$ & 0.9971 & 24 & 74 & 2.08 \\
\hline 10 & Gallik asit & $139.2 \pm 2.11$ & $\mathrm{y}=1.9995 \mathrm{x}+0.9041$ & 0.9985 & 21 & 60 & 1.55 \\
\hline 11 & Ferulik asit & $845.8 \pm 1.98$ & $y=1.5133 x+10.198$ & 0.9988 & 31 & 94 & 0.62 \\
\hline 12 & Sirinjic asit & $38.9 \pm 0.39$ & $y=2.0696 x+0.0417$ & 0.9992 & 29 & 88 & 0.28 \\
\hline 13 & Daidzein & $\mathrm{T}$ & - & - & 16 & 49 & 0.47 \\
\hline 14 & Krisin & $*$ & - & - & 35 & 104 & 1.52 \\
\hline 15 & Kemferol & $37.4 \pm 1.45$ & $y=0.9948 x+1.2839$ & 0.9974 & 12 & 35 & 1.85 \\
\hline 16 & Luteolin & $5.6 \pm 0.31$ & $y=247.11 x+47.917$ & 0.9993 & 6 & 19 & 2.19 \\
\hline 17 & Fisetin & $\mathrm{T}$ & - & - & 9 & 28 & 2.07 \\
\hline 18 & Morin & $1598.4 \pm 2.15$ & $y=39.941 x+341.46$ & 0.9994 & 23 & 69 & 0.88 \\
\hline 19 & Kersetin & $1416.0 \pm 1.83$ & $y=34.225 x+1813.4$ & 0.9988 & 11 & 34 & 0.65 \\
\hline 20 & 3-O-Metilkersetin & $60.5 \pm 0.94$ & $y=11.536 x+12.008$ & 0.9985 & 27 & 83 & 0.36 \\
\hline 21 & İzoramnetin & $492.8 \pm 0.38$ & $y=18.054 x+64.6$ & 0.9972 & 34 & 104 & 1.47 \\
\hline 22 & Galangin & $22.6 \pm 1.29$ & $y=259.14 x-44.5$ & 0.9962 & 23 & 71 & 2.15 \\
\hline 23 & Mirsetin & $4.7 \pm 0.88$ & $y=77.896 x+4.3804$ & 0.9992 & 19 & 59 & 0.73 \\
\hline 24 & Viteksin & $1.6 \pm 0.14$ & $y=254.92 x+26.189$ & 0.9974 & 8 & 23 & 1.92 \\
\hline 25 & Hesperidin & $7.4 \pm 1.08$ & $y=131.49 x-20.833$ & 0.9992 & 12 & 37 & 1.53 \\
\hline 26 & 3-Hidroksiflavon & $1.2 \pm 0.33$ & $y=5604.8 x+625$ & 0.9988 & 9 & 28 & 0.78 \\
\hline 27 & Naringenin & $9.9 \pm 0.78$ & $y=634.26 x+39.583$ & 0.9954 & 33 & 99 & 0.49 \\
\hline 28 & Genistein & $4.9 \pm 0.69$ & $y=93.898 x-4.1667$ & 0.9994 & 24 & 74 & 0.83 \\
\hline 29 & Rutin & $4.7 \pm 1.17$ & $y=1838.7 x+410.52$ & 0.9985 & 7 & 23 & 2.17 \\
\hline 30 & Fenil asetat & $19.2 \pm 1.36$ & $y=356.35 x+708.33$ & 0.9984 & 16 & 49 & 1.66 \\
\hline
\end{tabular}

Tablo 4. Anthemis tinctoria var. tinctoria bitkisine ait biyolojik aktivite sonuçları

\begin{tabular}{|c|c|c|c|c|c|c|c|}
\hline \multirow{2}{*}{ Biyolojik Aktivite } & \multicolumn{2}{|c|}{$\begin{array}{c}\text { Fenolik Madde } \\
\text { Miktar Tayini }\end{array}$} & \multicolumn{2}{|c|}{$\begin{array}{c}\text { Antioksidan } \\
\text { Aktivite }\end{array}$} & \multicolumn{2}{|c|}{$\begin{array}{c}\text { Antikolinesteraz } \\
\text { Aktivite }^{\mathrm{d}}\end{array}$} & \multirow[t]{2}{*}{$\begin{array}{c}\text { Antitirozinaz } \\
\text { Aktivite }^{\mathrm{d}}\end{array}$} \\
\hline & $\mathrm{TPC}^{\mathrm{a}}$ & $\mathrm{TFC}^{\mathrm{b}}$ & $\mathrm{DPPH}^{\mathrm{c}}$ & CUPRAC $^{\mathrm{c}}$ & AChE & $\mathrm{BuChE}$ & \\
\hline Metanol ekstresi & $21.7 \pm 4.2$ & $9.7 \pm 2.56$ & $302.18 \pm 2.74$ & $514.62 \pm 3.82$ & $254.7 \pm 4.86$ & $166.2 \pm 3.74$ & $415.7 \pm 1.85$ \\
\hline Galantamin $\mathrm{HBr}^{*}$ & - & - & - & - & $0.106 \pm 0.05$ & $1.04 \pm 0.12$ & - \\
\hline Kojik asit* & - & - & - & - & - & - & $7.9 \pm 0.54$ \\
\hline
\end{tabular}

\section{Tartışma ve Sonuçlar}

Çalışmamızda, Tire/İzmir' de yabani olarak yetişen Anthemis tinctoria var. tinctoria bitkisinin fenolik kompozisyonu, antioksidan kapasitesi ve çeşitli enzim inhibisyon aktiviteleri incelenmiştir. Bitkinin ekstraksiyonu için, analiz edilecek madde grubunun kimyasal yapısına bağlı olarak polar veya apolar karakterde farklı çözücüler kullanılabilir. Dolayısıyla, fenolik bileşiklerin bitkiden ekstraksiyonu için en uygun polar ve organik çözücü olarak metanol tercih edilmiştir.
Söz konusu türe ait, daha az sayıda bileşikle miktar tayini deneyi literatürde bulunmakla birlikte kapsamlı bir fitokimyasal tarama ilk kez tarafimızdan rapor edilmektedir. LC-MS/MS çalışmamızda, bileşiklerin tayini referans standartlar kullanılarak ve kütle fragmantasyonları esas alınarak gerçekleştirildi. Buna göre, benzoik asit türevlerinden 3-hidroksibenzoik asit ve ferulik asit, flavonoitlerden ise morin ve kersetin majör bileșikler olarak tespit edilmiștir. Majör bileşiklerin kromatogramları ve kütle bölünmeleri Şekil 3' de gösterilmiştir. Daha önce rapor edilen, 
Çankırı'dan toplanan aynı tür üzerinde yapılan çalışmada, 7 polifenolik maddenin (gallik asit, $p$ kumarik asit, 4-hidroksibenzoik asit, vanillik asit, rutin, kersetin ve naringenin) miktar tayini gerçekleştirilmiştir ve 4-hidroksibenzoik asit maddesi diğerlerine göre en yüksek oranda bulunmuştur (Eser vd., 2017). Bu madde miktarlarının bizim çalışmamızda farklı çıkmasının nedeni, oksidatif stres, tozlaşma, korunma gibi bitkiye ait faktörler olabileceği gibi çevresel etkenler de olabilir. Dolayısıyla farklı lokasyonlardaki aynı türlerin kendine özgü kimyasal profili ve biyolojik aktivitesi bulunabilir.

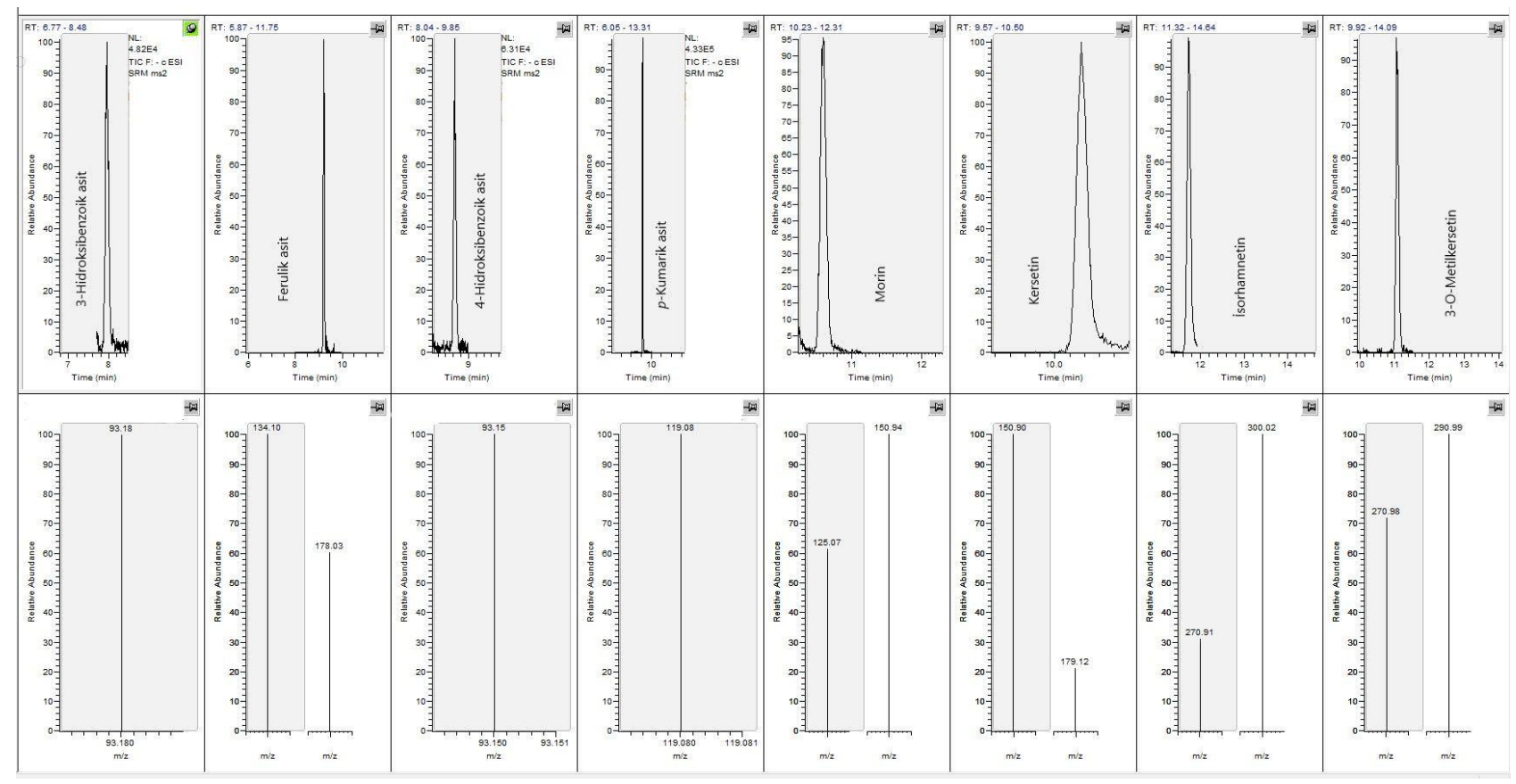

Şekil 3. Majör bileşiklerin kromatogramları ve kütle fragmantasyonları

Bitkide bulunan toplam biyoaktif maddelerin belirlenmesi amaciyla, spektrofotometrik olarak yapılan toplam fenolik ve flavonoit miktar tayini çalışmaları gerçekleştirilmiştir. Bu tür üzerinde bu tayinlerin rapor edildiği bir çalışma yoktur ancak, değerler diğer Anthemis türlerinde rapor edilen çalışmaların sonuçlarıyla uyumlu olarak bulunmuştur. Bunlara örnek olarak, A. stiparum subsp. sabulicola bitkisinde sirasiyla 13.6 (pirokateşol E/g) ve $5.9(\mathrm{QE} / \mathrm{g}$ ) (Chemsa vd., 2018), A. fumariifolia bitkisinde 31.94 (GAE/g) ve $12.88(\mathrm{QE} / \mathrm{g})$, A. cretica subsp. argaea bitkisinde $48.51 \quad(\mathrm{GAE} / \mathrm{g})$ ve 11.49 (QE/g) (Albayrak ve Aksoy, 2013), A. cotula bitkisinde ise 54.32 (GAE/g) ve 39.14 (RutinE/g) (Sut vd., 2019) değerlerini gösterebiliriz.

Miktar tayini dışında, örneğimizde asetilkolinesteraz, bütirilkolinesteraz ve tirozinaz enzimlerinin inhibisyon değerleri saptanmıştır. Literatürde bu Anthemis türüne ait açıklanan aktivitelerle ilgili bir çalışmaya rastlanmamıştır. Kisıtlı sayıda farklı Anthemis türleri (Chemsa vd., 2018; Sut vd., 2019; Orlando vd., 2019) üzerinde bu çalışmalar yapılmış olup değişken aralıkta aktivite saptanmıştır. Ancak bu çalışmalarda sonuçlar $\mathrm{IC}_{50}$ değeri üzerinden değil, \% inhibisyon veya kojik asit ve galantamin eşdeğeri olarak verilmiştir. Dolayısıyla çalıştığımız türün biyolojik aktivitesini diğer türlerle tam olarak karşılaştırmamız mümkün değildir. Bitkimizin enzim inhibisyon değerleri çok yüksek kapasitede bulunmamıştır ancak ekstrenin antikolinesteraz aktivitesine LC-MS/MS çalışmasında miktarlarını yüksek olarak belirlediğimiz morin ve kersetin bileşikleri pozitif olarak katkı sağlamış, düşük konsantrasyona sahip luteolin, kemferol, naringenin ve rutin bileşikleri ise negatif yönde etkilemiş olabilir. Zira, bu bileşiklerin güçlü antikolinesteraz aktiviteye sahip olduklarının belirtildiği çalışmalar literatürde bulunmaktadır (Katalinic vd., 2010; Remya vd., 2012). Bunun yanısıra, bu bileşiklerin birbirleriyle de etkileşime girebilecekleri de göz önünde bulundurulmalıdır. Antitirozinaz aktivitede ise fenolik asit grubundan yüksek konsantrasyondaki 4-hidroksibenzoik asit ve $p$-kumarik asit bileşiklerinin inhibisyon kapasitesini arttırmış olabileceği düşünülmektedir. Yine literatürde, bu bileşiklerin tirozinaz enziminin inhibisyonunda yer aldığı çalışmalar mevcuttur (Wang vd., 2011). 
Son olarak bitkinin antioksidan kapasitesini belirlemek amaciyla, radikal süpürücü aktivite DPPH metodu ve indirgeme gücü CUPRAC metodu ile çalışıldı. Sonuçların troloks ekivalanı olarak verildiği Anthemis türleri incelendiğinde, farklı ekstraksiyon yöntemleri uygulanan $A$. cotula bitkisinin DPPH deneyi sonuçları 66.87103.44, CUPRAC deneyi sonucu ise 307.66$435.32 \mathrm{mg}$ TE/g ekstre aralığında çıkmıştır. Dolayısıyla çalıştığımız türün her iki aktivitesi de daha yüksek bulunmuştur. A. tinctoria var. pallida ve $A$. cretica subsp. tenuiloba türlerinin incelendiği başka bir çalışmada, metanol ekstrelerine ait DPPH deneyi sonuçları sirasıyla 407.07 ve 97.22, CUPRAC deneyi sonuçları ise 691.17 ve $223.09 \mathrm{mg} \mathrm{TE} / \mathrm{g}$ ekstre olarak rapor edilmiş olup, bitkimizin antioksidan aktivitesi birinci türden düşük ikincisinden ise yüksek gözlenmiştir. Sonuç olarak, yapılan çalışmada İzmir kaynaklı Anthemis tinctoria var. tinctoria türü fitokimyasal olarak incelenmiş olup, bitkinin biyoaktif moleküller için kaynak olabileceği belirlenmiştir.

\section{Kaynaklar}

Afanasev, I.B., Dcrozhko, A.I., Brodskii, A.V., Kostyuk, V.A. ve Potapovitch, A.I., 1989. Chelating and Free Radical Scavenging Mechanisms of Inhibitory Action of Rutin and Quercetin in Lipid Peroxidation. Biochemical Pharmacology, 38, 1763-1769.

Afifi, F.U. ve Kasabri, V., 2013. Pharmacological and Phytochemical Appraisal of Selected Medicinal Plants from Jordan with Claimed Antidiabetic Activities. Scientia Pharmaceutica, 81(4), 889932.

Albayrak, S. ve Aksoy, A., 2013. Evaluation of Antioxidant and Antimicrobial Activities of Two Endemic Anthemis Species in Turkey. Journal of Food Biochemistry, 37(6), 639-645.

Al-Snafi, A.E., 2016. Medical Importance of Anthemis nobilis (Chamaemelum nobile)-A review. Asian Journal of Pharmaceutical Science and Technology, 6(2), 89-95.

Apak, R., Güçlü, K., Özyürek, M. ve Çelik, S.E., 2008. Mechanism of Antioxidant Capacity Assays and the CUPRAC (Cupric Ion Reducing Antioxidant Capacity) Assay. Microchimica Acta, 160(4), 413-419.

Asanuma, M., Miyazaki, I. ve Ogawa, N., 2003. Dopamine- or L-DOPA-Induced Neurotoxicity: The Role of Dopamine Quinone Formation and Tyrosinase in a Model of Parkinson's Disease. Neurotoxicity Research, 5(3), 165-76.
Baytop, T., 1999. Türkiye'de Bitkilerle Tedavi, Geçmişte ve Bugün: İstanbul, Nobel Tip Kitabevi, s. 313.

Blois, M.S., 1958. Antioxidant Determinations by the Use of a Stable Free Radical. Nature, 181, 11991200 .

Bremer, K. ve Humpries, C.J., 1993. Generic Monograph of the Asteraceae-Anthemideae. Bulletin of the Natural History Museum, 23(2), 71-177.

Bursal, E., Aras, A., Kılıç, A. ve Buldurun, K., 2020. Chemical Constituent and Radical Scavenging Antioxidant Activity of Anthemis Kotschyana Boiss. Natural Product Research, doi: 10.1080/14786419.2020.1723089.

Cakilcioglu, U., Khatun, S., Turkoglu, I. ve Hayta, S., 2011. Ethnopharmacological Survey of Medicinal Plants in Maden (Elazig-Turkey). Journal of Ethnopharmacology, 137, 469-486.

Chemsa, A.E., Zellagui, A., Öztürk, M., Erol, E., Ceylan, O., Duru, M. E. ve Lahouel, M., 2018. Chemical Composition, Antioxidant, Anticholinesterase, Antimicrobial and Antibiofilm Activities of Essential Oil and Methanolic Extract of Anthemis stiparum subsp. sabulicola (Pomel) Oberpr. Microbial Pathogenesis, 119(March), 233-240.

Conforti, F., Menichini, F., Formisano, C., Rigano, D., Senatore, F., Bruno, M., Rosselli, S. ve Çelik, S., 2012. Anthemis wiedemanniana Essential Oil Prevents LPS-Induced Production of NO in RAW 264.7 Macrophages and Exerts Antiproliferative and Antibacterial Activities in vitro. Natural Product Research, 26(17), 15941601.

De Mieri, M., Monteleone, G., Ismajili, I., Kaiser, M. ve Hamburger, M., 2017. Antiprotozoal Activity-Based Profiling of a Dichloromethane Extract from Anthemis Nobilis Flowers. Journal of Natural Products, 80(2), 459-470.

Dziri, S., Hassen, I., Fatnassi, S., Mrabet, Y., Casabianca, H., Hanchi, B. ve Hosni, K., 2012. Phenolic Constituents, Antioxidant and Antimicrobial Activities of Rosy Garlic (Allium roseum var. odoratissimum). Journal of Functional Foods, 4(2), 423-432.

Ellman, L., Courtney, K.D., Andres, Jr V. ve Featherstone, R.M., 1961. New and Rapid Colorimetric Determination of Acetylcholinesterase Activity. Biochemical Pharmacology, 7, 88-95.

Emir, A., Emir, C. ve Yıldırım, H., 2020a. Characterization of Phenolic Profile by LC-ESIMS / MS and Enzyme Inhibitory Activities of 
Two Wild Edible Garlic: Allium Nigrum L. and Allium Subhirsutum L. The Journal of Food Biochemistry, 44(4), e13165.

Emir, A., Emir, C. ve Yıldırım, H., 2020b. Chemical and Biological Comparison of Different Parts of two Allium Species: Allium Paniculatum L. Subsp. Villosulum (Hal.) Stearn and Allium Paniculatum L. Subsp. Paniculatum L. Chemical Papers, doi: 10.1007/s11696-02001311-1.

Eser, F., Yaglioglu, A.S., Dolarslan, M., Aktas, E. ve Onal, A., 2017. Dyeing, Fastness, and Cytotoxic Properties, and Phenolic Constituents of Anthemis Tinctoria Var. Tinctoria (Asteraceae). The Journal of The Textile Institute, 108(9), 1489-1495.

Gonçalves, S. ve Romano, A., 2017. Inhibitory Properties of Phenolic Compounds Against Enzymes Linked with Human Diseases, in: Soto-Hernández, M. (Ed), Phenolic Compounds - Biological Activity. IntechOpen, London, pp. 99-118.

Güner, A., Özhatay, N., Ekim, T. ve Başer, K.H.C., 2000. Flora of Turkey and The East Aegean Islands: Edinburgh, Edinburgh University Press, pp. 92-94.

Honda, G., Yesilada, E., Tabata, M., Sezik, E., Fujita, T., Takeda, Y., Takaishi, Y. ve Tanaka, T., 1996. Traditional Medicine in Turkey. VI. Folk Medicine in west Anatolia: Afyon, Kütahya, Denizli, Muğla, Aydin provinces. Journal of Ethnopharmacology, 53(2), 75-87.

Hopkins, A.L. ve Groom, C.R., 2002. The Druggable Genome. Nature Reviews Drug Discovery, 727730 .

Karim, A., Berrabah, M., Mekhfi, H., Ziyyat, A., Legssyer, A., Bouali, A., Haloui, B., Amrani, S. ve Aziz, M., 2010. Effect of Essential Oil of Anthemis Mauritiana Maire \& Sennen Flowers on Intestinal Smooth Muscle Contractility. Journal of Smooth Muscle Research, 46(1), 6575 .

Katalinic, M., Rusak, G., Baroviç, J.D., Sinko, G., Jelic, D., Antolovic, R. ve Kovarik, Z., 2010. Structural Aspects of Flavonoids as Inhibitors of Human Butyrylcholinesterase. European Journal of Medicinal Chemistry, 45(1), 186-192.

Lattanzio, V., 2013. Phenolic Compounds: Introduction, in: Ramawat, K.G., Merillon, J.M. (Eds.), Handbook of Natural Products. SpringerVerlag Berlin Heidelberg, pp. 1544-1573.

Martinez, M.V. ve Whitaker, J.R., 1995. The Biochemistry and Control of Enzymatic
Browning. Trends in Food Science \& Technology, 6, 195-200.

Masuda, T., Yamashita, D., Takeda, Y. ve Yonemori, S., 2005. Screening for Tyrosinase Inhibitors Among Extracts of Seashore Plants and Identification of Potent Inhibitors from Garcinia Subelliptica. Bioscience, Biotechnology, and Biochemistry, 69(1), 197-201.

Orhan, I., Deliorman-Orhan, D. ve Özçelik, B., 2009. Antiviral Activity and Cytotoxicity of The Lipophilic Extracts of Various Edible Plants and Their Fatty Acids. Food Chemistry, 115, 701705 .

Orlando, G., Zengin, G., Ferrante, C., Ronci, M., Recinella, L. ve Menghini, L., 2019. Comprehensive Chemical Profiling and Multidirectional Biological Investigation of Two Wild Anthemis Species (Anthemis tinctoria var. pallida and A. cretica subsp. tenuiloba): Focus on Neuroprotective Effects. Molecules, 24, 2582.

Özek, G., Özbek, M.U., Yur, S., Göger, F., Arslan, M. ve Özek, T., 2019. Assessment of Endemic Cota fulvida (Asteraceae) for Phytochemical Composition and Inhibitory Activities Against Oxidation, $\alpha$-amylase, Lipoxygenase, Xanthine Oxidase and Tyrosinase Enzymes. Records of Natural Products, 13(4), 333-345.

Papaioannoua, P., Lazaria, D., Kariotib, A., Soulelesa, C., Heilmannc, J., Hadjipavlou-Litinad, D. ve Skaltsa, H., 2007. Phenolic Compounds with Antioxidant Activity from Anthemis tinctoria L. (Asteraceae). Zeitschrift für Naturforschung CA Journal of Biosciences, 62c, 326-330.

Remya, C., Dileep, K.V., Tintu, I., Variyar, E.J. ve Sadasivan, C., 2012. Design of Potent Inhibitors of Acetylcholinesterase Using Morin As The Starting Compound. Frontiers in Life Science, 6(3), 107-117.

Shawahna, R. ve Jaradat, N.A., 2017. Ethnopharmacological Survey of Medicinal Plants Used by Patients With Psoriasis in The West Bank of Palestine. BMC Complementary and Alternative Medicine, 17(1), 4.

Singleton, V.L., Orthofer, R. ve Lamuela-Raventos, R.M., 1999. Analysis of Total Phenols and Other Oxidation Substrates and Antioxidants by Means of Folin-Ciocalteu Reagent. Methods in Enzymology, 299, 152-178.

Sut, S., Dall'Acqua, S., Zengin, G., Senkardes, I., Bulut, G., Cvetanović, A. ve Mahomoodally, F. 2019. Influence of Different Extraction Techniques on the Chemical Profile and Biological Properties of Anthemis cotula L.: Multifunctional Aspects for Potential 
Pharmaceutical Applications. Journal of Pharmaceutical and Biomedical Analysis, 173(May), 75-85.

Ugurlu, E. ve Secmen, O., 2008. Medicinal Plants Popularly Used in The Villages of Yunt Mountain (Manisa-Turkey). Fitoterapia, 79(2), 126-131.

Wang, H.M., Chou, Y.T., Hong, Z.L., Chen, H.A., Chang, Y.C., Yang, W.L., Chang, H.C., Mai, C.T. ve Chen, C.Y., 2011. Bioconstituents From Stems of Synsepalum Dulcificum Daniell (Sapotaceae) Inhibit Human Melanoma Proliferation, Reduce Mushroom Tyrosinase Activity and Have Antioxidant Properties. Journal of the Taiwan Institute of Chemical Engineers, 42, 204-211.

Weinstock, M., 1999. Selectivity of Cholinesterase Inhibition: Clinical Implications for The Treatment of Alzheimer's Disease. CNS Drugs, 12(4), 307-323.

Zolghadri, S., Bahrami, A., Hassan Khan, M.T., Munoz-Munoz, J., Garcia-Molina, F., GarciaCanovas, F. ve Saboury, A.A., 2019. A Comprehensive Review on Tyrosinase Inhibitors. Journal of Enzyme Inhibition and Medicinal Chemistry, 34(1), 279-309. 